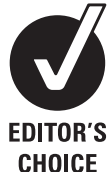

CHOICE

\title{
'It was a freak accident': an analysis of the labelling of injury events in the US press
}

\author{
Katherine C Smith, ${ }^{1,2}$ Deborah C Girasek, ${ }^{3}$ Susan P Baker, ${ }^{1,4}$ Jennifer A Manganello, ${ }^{5}$ \\ Stephen M Bowman, ${ }^{1,4}$ Alicia Samuels, ${ }^{1}$ Andrea C Gielen ${ }^{1,2}$
}

1Johns Hopkins Center for Injury Research and Policy, Johns Hopkins Bloomberg School of Public Health, Baltimore, MD, USA

${ }^{2}$ Department of Health, Behavior and Society, Johns Hopkins Bloomberg School of Public Health, Baltimore, MD, USA ${ }^{3}$ Department of Preventive Medicine and Biometrics, Uniformed Services University of the Health Sciences, Bethesda, MD, USA

${ }^{4}$ Department of Health Policy and Management, Johns Hopkins Bloomberg School of Public Health, Baltimore, MD, USA

${ }^{5}$ School of Public Health, Department of Health Policy. Management and Behavior, University at Albany, SUNY Rensselaer, NY, USA

\section{Correspondence to} Katherine Clegg Smith, Johns Hopkins University, $624 \mathrm{~N}$. Broadway, Room 726 Hampton House, Baltimore, MD 21205, USA; kasmith@jhsph.edu

Accepted 9 May 2011 Published Online First 9 June 2011

\section{ABSTRACT}

Objectives Given that the news media shape our understanding of health issues, a study was undertaken to examine the use by the US media of the expression 'freak accident' in relation to injury events. This analysis is intended to contribute to the ongoing consideration of lay conceptualisation of injuries as 'accidents'.

Methods LexisNexis Academic was used to search three purposively selected US news sources (Associated Press, New York Times and Philadelphia Inquirer) for the expression 'freak accident' over 5 years (2005-9). Textual analysis included both structured and open coding. Coding included measures for who used the expression within the story, the nature of the injury event and the injured person(s) being reported upon,

incorporation of prevention information within the story and finally a phenomenological consideration of the uses and meanings of the expression within the story context. Results The search yielded a dataset of 250 human injury stories incorporating the term 'freak accident'. Injuries sustained by professional athletes dominated coverage (61\%). Fewer than 10\% of stories provided a clear and explicit injury prevention message. Stories in which journalists employed the expression 'freak accident' were less likely to include prevention information than stories in which the expression was used by people quoted in the story.

Conclusions Journalists who frame injury events as freak accidents may be an appropriate focus for advocacy efforts. Effective prevention messages should be developed and disseminated to accompany injury reporting in order to educate and protect the public.

\section{INTRODUCTION}

The use of 'accident' to describe injury events has been problematised by many injury experts because it is thought to convey notions of randomness and unpredictability, thus discouraging injury prevention initiatives. ${ }^{1-3}$ Debate over this issue continues, despite mounting evidence that such concerns may be misplaced. Public surveys conducted in Brazil, Canada and the USA have all demonstrated that the expression 'accident' does not appear to be associated with an assessment that an injuryproducing event was unpreventable. ${ }^{4-6}$ We examine how the news media use 'freak accident' in covering injury events. We will consider what meaning this expression conveys in the context of print journalism and what objectives are served by its use.

News organisations are influential in shaping societal discourse on health issues. News media are a significant source of health information and have been associated with important behavioural and policy changes. ${ }^{7-11}$ In relation to injury, news media contribute to defining what events and issues should be considered 'risky'12 and where and with whom risk lies. Scholarly work documenting news media coverage of injuries is, however, still in its infancy, and the relationship between media framing and public attitudes towards injury topics has not been sufficiently explored. ${ }^{13-15}$

To our knowledge, this is only the second examination of media characterisations of 'accidents ${ }^{\prime 12}$ and is the first to consider any modifier of the expression 'accident' in relation to injury events. This study is therefore intended to be entirely exploratory, aiming to generate hypotheses and avenues for further research rather than definitive findings. Our exploration is shaped by the following research questions:

- What types of injury events are described as 'freak accidents' in the US news media?

- In the news media environment, who uses the expression 'freak accident' to describe injury events?

- Do 'freak accident' news stories convey prevention information?

- What purpose does using the expression 'freak accident' seem to serve for those who use it?

\section{METHODS}

\section{Qualitative sample construction}

LexisNexis Academic (http://www.academic.lexisnexis.com/online-services/academic/academic-

content-news.aspx) was used to collect news data. A small and purposive sample of three US news sources (Associated Press (AP), New York Times and Philadelphia Inquirer) that serve as a proxy for the wider news media was compiled for the purpose of this study. We selected AP because of its considerable influence as a story source for print and other news media in the US context and beyond. We added two daily newspapers because they were easily accessible and because their mandate includes coverage of local events, which would include injury events in their locality. We used a single search term 'freak accident', identifying stories that included this expression anywhere in the text. The initial dataset included 400 stories from which 150 were excluded because they dealt with fictional injuries (such as reviews of novels or plays), non-human injuries (such as an injury to a race horse) or an 'accidental' event that was unrelated to injury. Distinct stories of a single injury event (such as a developing story over time) were retained, but exact replica stories on the same event in one outlet were excluded. 


\section{Text analysis}

A text analysis was conducted that combined structured and open coding. First, story subsets were collectively reviewed by the authors and a consensus as to areas and issues of interest was developed. During this initial review it was discovered that many stories focused on injuries sustained by professional athletes. This finding guided further development of appropriate and detailed coding categories for sporting injuries in addition to overall coding.

To facilitate formal coding, author A developed a codebook that included eight quantitative and two qualitative measures. The codebook was then provided to two independent coders, one of whom is a working journalist and the other a health communication expert (author D). The coders applied the framework to a set of 30 news stories and then discussed coding discrepancies with author A, after which the codebook was refined and finalised (table 1 ). Subsequent inter-rater reliability was calculated for the quantitative variables by double-coding a sample of $10 \%$ of stories (half at the outset of coding and half at the completion); kappa statistics demonstrated excellent concordance $(>0.75)$ for all but one quantitative variable (level of sports engaged in), which was subsequently dropped from the analysis.

The two qualitative measures employed in the analysis ('prevention content' and 'phenomenological analysis') were refined following the initial structured coding using open-ended notes made by the coders when reviewing each story. We created the 'prevention content' variable by recoding notes made by the coders pertaining to prevention content into three categories: 'clear prevention message', 'no prevention message' and

Table 1 Descriptive coding

\begin{tabular}{|c|c|c|}
\hline Variable & Coding options/rules & $\mathbf{N}(\%)$ \\
\hline \multirow[t]{3}{*}{ News source } & Associated Press & $175(70)$ \\
\hline & New York Times & $37(15)$ \\
\hline & Philadelphia Inquirer & $38(15)$ \\
\hline \multicolumn{3}{|l|}{ Single injury event } \\
\hline Is there a distinct injury event being discussed? & Yes & $220(88)$ \\
\hline Code 'No' if the story is more thematic & No & $30(12)$ \\
\hline \multicolumn{3}{|l|}{ Freak accident focus } \\
\hline \multirow{2}{*}{$\begin{array}{l}\text { Is the majority of the story focused on the freak } \\
\text { accident event OR do the headline and story } \\
\text { lead focus on the injury? }\end{array}$} & Yes & $140(56)$ \\
\hline & No & $110(44)$ \\
\hline \multicolumn{3}{|l|}{ Use of term } \\
\hline \multirow{8}{*}{$\begin{array}{l}\text { Who is employing the term 'freak accident' } \\
\text { (in quotes/attributed)? }\end{array}$} & Journalist/person writing article & $102(41)$ \\
\hline & Injured person & 47 (19) \\
\hline & Coach & $18(7)$ \\
\hline & Team mate & $12(5)$ \\
\hline & Family member of the injured person & $12(5)$ \\
\hline & Owner & $11(5)$ \\
\hline & Spokesperson (agency, team, etc) & $11(5)$ \\
\hline & Other & $6(3)$ \\
\hline \multirow[t]{2}{*}{ Medical treatment } & $\begin{array}{l}\text { Yes (write in who provided treatment } \\
\text { if mentioned) }\end{array}$ & $122(55)$ \\
\hline & No or not clear or not indicated/not discussed & $98(45)$ \\
\hline \multirow[t]{4}{*}{ Age of injured person } & $\begin{array}{l}\text { Yes: injured person is } \leq 17 \text { years (use for } \\
\text { high school players) }\end{array}$ & $21(9.5)$ \\
\hline & $\begin{array}{l}\text { No: injured person } \geq 18 \text { years (use for college } \\
\text { players or professional athletes) }\end{array}$ & \\
\hline & $\begin{array}{l}\text { Injured person appears to be an adult but no } \\
\text { age is provided }\end{array}$ & \\
\hline & Not clear or not indicated & \\
\hline \multirow[t]{3}{*}{ Injury happened in or around a home? } & Yes & $24(11)$ \\
\hline & No & \\
\hline & Not indicated & \\
\hline \multirow[t]{3}{*}{ Injured person a professional? } & Yes (including Olympic athletes) & $134(61)$ \\
\hline & No & \\
\hline & Not clear/indicated & \\
\hline \multirow{4}{*}{$\begin{array}{l}\text { Circumstances of injury event? Only coded for } \\
\text { subset where injured person is a professional athlete. }\end{array}$} & During competition & $54(40)$ \\
\hline & During practice & $32(34)$ \\
\hline & Not during sports activity & $29(21)$ \\
\hline & Not clear or not indicated & $19(14)$ \\
\hline \multirow[t]{4}{*}{ Prevention content } & Open coding then recoded (see table 2): & \\
\hline & Yes & \\
\hline & No & \\
\hline & $\begin{array}{l}\text { Ambiguous (either unspecific talk of prevention } \\
\text { or extensive discussion of cause) }\end{array}$ & \\
\hline \multicolumn{3}{|l|}{ Phenomenological consideration of 'freak accident' } \\
\hline $\begin{array}{l}\text { How do people account for when things go wrong } \\
\text { or explain why it happened? Why is someone } \\
\text { using the term 'freak accident'? }\end{array}$ & Open coding then recoded (see table 3 ) & \\
\hline
\end{tabular}


'ambiguous' (the 'ambiguous' category captured stories such as those where the description of the event included some reference to potential contributing factors, but without any explicit messages about prevention). The creation of a categorical variable facilitated consideration of whether prevention messages were more prevalent in stories about children's injuries, from a particular news outlet or in which the expression was employed by a journalist versus a stakeholder in the injury event (table 2).

The 'phenomenological analysis' of 'freak accident' was an explicit consideration of the use of this expression to construct meaning around the injury event. We used this variable to explore the boundaries of the concept as employed in the news media rather than to quantify frequency of occurrence. Our ultimate aim in this was to construct a typology of the meanings and uses of 'freak accident' in the news media (table 3). The qualitative coding of this variable took place in three stages: (1) author A elucidated a range of 'meanings and uses' based on a review of all articles; (2) the coders used these to guide (but not determine) their open coding of the articles; (3) author A used coders' notes to develop a typology of meanings and uses of the expression. The larger authorship team also provided input at each stage.

\section{RESULTS}

The final dataset contained 250 relevant news stories. The AP contributed 175 stories (70\%), the New York Times $37(15 \%)$ and the Philadelphia Inquirer 38 (15\%) (table 1). Just over half of the stories $(n=140,56 \%)$ were focused primarily on the injury event described as a 'freak accident', rather than simply mentioning an injury event as part of a larger story.

From our dataset of 250 stories, 30 were excluded from the analysis of specific injury events because, while they made mention of 'freak accidents' in relation to human injury, they did so without reference to one single injury event. For example, our dataset included a story discussing the content of morning television shows and mentioned that victims of a 'freak accident' were typical guests. This story was relevant and thus included in the overall sample, but it could not be coded in terms of who was the injured party as injury was talked about in concept only. Similarly, while we included stories such as one describing the practice of decorating graves of people who had died from 'freak accidents', we could not fully code such articles as there was no specific injury event described.

Table 2 Prevention content

\begin{tabular}{llll}
\hline & $\begin{array}{l}\text { No prevention } \\
\text { content, } \mathbf{n}(\%)\end{array}$ & $\begin{array}{l}\text { Ambiguous } \\
\text { prevention } \\
\text { content, } \mathbf{n}(\%)\end{array}$ & $\begin{array}{l}\text { Clear } \\
\text { prevention } \\
\text { content, } \mathbf{n}(\%)\end{array}$ \\
\hline $\begin{array}{l}\text { Overall dataset } \\
\text { Stories with specific } \\
\text { injury events (n=220) }\end{array}$ & $206(82)$ & $24(9.5)$ & $20(8)$ \\
News outlet & $185(84)$ & $19(8.5)$ & $17(8)$ \\
$\quad$ Associated Press & $149(85)$ & $28(73)$ & $13(7.5)$ \\
$\quad$ New York Times & $28(73)$ & $7(18)$ & $3(8)$ \\
$\quad$ Philadelphia Inquirer & $30(79)$ & $4(10.5)$ & $4(10.5)$ \\
$\begin{array}{l}\text { Expression source in story } \\
\text { Journalist }\end{array}$ & $91(89)$ & $7(7)$ & $4(4)$ \\
$\quad$ Ouoted stakeholder & $114(78)$ & $17(12)$ & $15(10)$ \\
Injured person & $117(82)$ & $5(4)$ & $12(9)$ \\
$\quad \begin{array}{l}\text { Professional athlete } \\
\text { Not professional athlete }\end{array}$ & $68(78)$ & $14(16)$ & $5(6)$ \\
\hline
\end{tabular}

Approximately $60 \%(n=134)$ of the stories dealing with a specific event focused on professional athletes' injuries. These athletic injuries occurred most frequently during competition ( $n=54,40 \%$ ), but athletes were also injured during practice $(n=32,34 \%)$ and during activities unrelated to paid work, such as in 'horseplay', fights or while engaged in other recreational sports $(n=29,21 \%)$.

Of the 220 stories that focused on a specific injury event, 122 (55\%) described some provision of medical treatment (eg, getting stitches or an x-ray). In 21 stories (10\%) there was discussion of a child's injury and, in 24 stories (11\%), injuries were reported as occurring at home. Of the 24 'home' injuries, seven involved children. Thus, $33 \%$ of child injuries reported on as 'freak accidents' occurred at home compared with only $8 \%$ of adult injuries. The three news outlets differed (approaching significance) in relation to the proportion of the 'freak accident' stories published pertaining to children, with a greater proportion of such stories appearing in the Philadelphia Inquirer $\left(\chi^{2}=5.32, \mathrm{df}(2), \mathrm{p}=0.07\right)$.

In 102 stories (41\%) the expression 'freak accident' appeared in the story as part of the journalist's prose rather than as part of a quote from a source. The following is from one such story.

Rose scored 15 points and had seven assists, along with a few anklebreaking moves, playing in the aftermath of a freak accident. Rose said he rolled over on a knife that he had left on his bed after cutting an apple on Monday evening. The resulting wound slashed into his left forearm, requiring 10 stitches. (New York Times, 10 December 2008)

Injured parties used the expression in 47 stories (19\%) and coaches, managers and team mates in 30 (12\%).

Myers was scheduled to pitch Saturday, but he fell stepping out of his car Friday night and injured his eye. Initially Myers said he was hurt playing catch with his 4-year-old son. 'It was a freak accident; that is all that I can say about it', Myers said. 'It's something you don't expect to happen and now you just try and be more cautious'. (Associated Press, 21 August 2009).

Holtz (coach) confirmed that running back Dominique Lindsay, who was expected to replace NFL first-round draft pick Chris Johnson at tailback, will miss the season after injuring a knee during a 'freak accident' collision with linebacker Quentin Cotton during preseason camp. (Associated Press, 25 August 2008).

In 22 stories (9\%), 'freak accident' was used to describe an injury event by someone in an ownership or spokesperson role.

'I think that it is just one of those terrible, sad freak accidents', said Lynne Loresch, executive director of the Mental Health Association of Washington County, the group home operator. (Associated Press, 18 April 2008, story about fatal minibus crash)

Among the subset of 220 stories that discussed a specific injury event, 185 (84\%) included no prevention information, 19 (9\%) included ambiguous information (such as warnings that people might have been given or safety measures that had been in place and presumably had failed) and 17 (8\%) included clear prevention messages (such as discussions about the protection afforded by wearing ski helmets following Natasha Richardson's death). Stories in which the journalist employed the expression 'freak accident' were significantly less likely to include any prevention content than those in which the expression was used by a quoted stakeholder $\left(\chi^{2}=5.4, \mathrm{df}(1), \mathrm{p}<0.05\right)$.

Stories in which the injured person was a professional athlete were less likely than stories about any other injured party to include any prevention content $\left(\chi^{2}=3.24, \mathrm{df}(1), \mathrm{p}=0.07\right)$. There 
Table 3 Meanings and uses of 'freak accident'

\begin{tabular}{ll}
\hline Meanings conveyed definition & Source and event context \\
\hline Unpredictable & \\
$\begin{array}{ll}\text { In the context of describing how an event would not } & \text { NYT 6/2/2007: Death of a dancer from Streb Extreme } \\
\text { have been predicted or expected given prior } & \text { Action troupe }\end{array}$
\end{tabular}

\section{Unexplainable}

Employed as part of an account of an event as unexplainable or an ongoing mystery.

Bizarre/grotesque

To give priority to the 'freakish' nature of the injury sustained

Action troupe

AP 9/6/2006: A child in an amusement park hit by a stray bullet, assumed shot from outside of park

PI 4/6/2008: Baseball player's hand injury experiences or expectations about the situation

AP 2/28/2007: Basketball injury that will keep the player out for approximately a year

o convey a sense of an event being extremely unusual. An event is 'freakish' because it occurs so infrequently

\section{Severe}

Expressing injury severity. The expression conveys rarity or unpredictability of the event's outcome rather than the event itself

Uses of expression definition

Minimisation of event

To suggest that this type of event is not worth attending to, therefore negating any need for an analysis of what went wrong and potential prevention mechanisms

Deflect responsibility (from injured person) To deflect responsibility from one or more stakeholders in the injury event. Such deflection relies on many of the 'meaning' concepts outlined above (that an event is unpredictable, rare and also unexplainable).

Deflect responsibility (from owner/manager)

Deflect responsibility (from another person involved)

Deny intent

To convey a lack of intent. Used in relation to someone who might be held responsible-in some cases the injured person
AP 3/27/2008: Injury to a football player with a reputation for 'bad' behaviour that will keep him out of play for 4 months AP 6/4/2008: The return of pitcher to the minor leagues after many prior injuries

AP 11/19/2007:

AP $11 / 25 / 2005$

Sisters injured by an escaped parade balloon

NYT 7/5/2007: Baby drowning in bath after being left with a toddler to supervise

PI 10/30/2007: NHL player suspended for hitting a player during play and causing concussion and a broken nose
Illustrative quotes

"It was a freak accident", said the company's founder Elizabeth Streb. "It was one of our more benign pieces, if there is such a thing. She just was in a sense too close to the ground to save the manner she was falling".

'It's still being investigated, but l'm pretty sure that it is going to wind up being a freak accident'.

'Navarro was heading into the dugout after the second inning and missed a step on his way to the bench, according to the Associated Press. OK, been there done that. To brace his fall, Navarro reached for something to grab hold of and cut open his hand on the netting designed to protect players from foul balls. It was not designed, however, to protect against clumsiness. "I almost threw up when I saw it", said Navarro'.

"'He came down on the leg without any contact with anybody. It's a freak accident, that's for sure", said Daly, who had rarely seen anything similar in 24 years of practice'.

'Blake has advanced to at least the third round of the US Open in his last seven appearances, he missed 2004 after breaking his neck in a freak accident when he ran into a net post but has yet to get past the quarterfinals of any major'.

'Mayweather (39-0, $25 \mathrm{KOs})$ insists that he was injured in a 'freak accident' in training, but won't say much else. "Believe me, it wasn't a small guy that done it, but it didn't come from sparring", Mayweather said. "When it happened, I tried to work through it. I was sparring for a while, but then it happened again". I said, "You know, I can't try to be a superhero. I've got to take time off and let it heal. I'd never tell exactly what happened. I just had a rib injury"'.

'Marshall said he understands that the public might be suspicious of his explanation, figuring instead that he got hurt in a street fight or in a bar room altercation. But he swore that it was just a freak accident ... "It was just horse playing, what brothers do". Marshall said. "We're adults, I just turned 24 on Sunday. He's 25. He's my brother. I love him to death. We were just playing around like usual"'.

'Zumaya was expected to be a key part of the Detroit bull pen in 2008 but underwent shoulder surgery after a freak accident during the off season. With wildfires threatening his home in Chula Vista, Calif, Zumaya was hurriedly removing treasured items from the attic. Unaware he was holding two boxes above his head at once, the top one slid off and slammed into his pitching shoulder'.

Headline '1 dead, about 30 hurt in South Carolina bus crash; bus company calls it 'freak accident'.

'The family won't sue because it was 'a freak accident' and "accidents just happen", he said' (father quoted)

"'I thought maybe it was a freak accident", he said.

"Maybe the baby slipped under the water for a minute"'. (Quote from neighbour who tried to revive the baby)

I am a little on the disappointment side. I think Mr. Campbell is in a tough situation on making this decision in regards to the last couple of incidents involving the Flyers. I think that he saw my point of view where this was not intentional. This was just a freak accident which unfortunately resulted in injury'. 
were no differences in prevention information by media outlet, nor was the likelihood of prevention content associated with child injuries (table 2).

Qualitative coding revealed five distinct meanings and three different purposes incorporated in the use of 'freak accident' to describe an injury event either by the journalist or someone quoted in the story (table 3). Our analysis showed that this expression could be used to present injury events as unpredictable, unexplainable, bizarre, grotesque, rare or severe. In many stories, journalists and various stakeholders were able to employ 'freak accident' in order to deflect responsibility, deny intent or minimise the severity of the event.

\section{DISCUSSION}

We examined how and why injury events are framed as 'freak accidents' in the news media. This analysis was not designed to determine whether the appearance of 'freak accident' in news media has a negative public health impact. The aim was to contribute to the limited empirical literature on lay discourse on injury in order to inform prevention efforts.

Our analysis of 'freak accident' news stories revealed a general absence of explicit injury prevention content in such stories. Moreover, stories in which journalists labelled an event a 'freak accident' (rather than the expression appearing in a quote from someone involved in the event) were significantly less likely to include prevention information. We also saw little or no evidence of injury prevention specialists contributing to these stories. It seems clear that the stories in this sample represent missed opportunities for promoting safety, which is consistent with the findings of previous studies of injury coverage. ${ }^{14} 15$

Notions of rarity and unpredictability evident in this analysis suggest that there may be potential benefit in educational outreach with journalists (especially sports journalists) with regard to injury epidemiology and prevention, and a potential need for injury prevention specialists to create relationships with these journalists. Such partnerships would facilitate the use of potentially newsworthy injury events as opportunities for prevention communication.

The idea of issue 'newsworthiness' came to shape our analysis in important ways. The label 'freak accident' can be understood as a tool employed by journalists to create interest and convey newsworthiness for an injury event that would otherwise not warrant coverage. A routine injury is, by its very nature, not 'news' whereas a 'freak accident', given the right injured person and context, may be a story worthy of attention. The expression 'freak accident' also conveyed severity of outcome, sometimes calling attention to the gruesome nature of an injury. Threats that are out of the ordinary (unusual or exotic) are more likely to provoke concern than risks that are faced on a regular basis. ${ }^{16}$ The extent to which framing an injury event as a 'freak accident' in order to convey newsworthiness is palatable to the injury prevention community is worth further consideration.

We were struck by the dominance of injuries to professional athletes in our news sample-both during competition and practice as well as injuries occurring 'off the field'. This finding suggests that partnering with sports journalists may prove particularly fruitful in terms of shaping injury-pertinent discourse in the media. While we are aware that these data are the result of a search for a 'freak accident' rather than all news reports on injuries, we conclude that athletes' injuries may be more newsworthy than those of people whose work does not depend on peak physical fitness. The dominance of athletes' injuries draws attention to the practice of framing injuries that occur in the course of routine play as 'freak accidents'.
Guttman ${ }^{17}$ argued that societal fondness for sports is paradoxical, as many sports entail a level of interpersonal violence that would be unsanctioned in most other areas of social life. Moreover, the physical exertion necessary for professional success frequently pushes athletes to the point of physical harm. Framing sporting injuries as 'freak accidents' might be appropriately understood as an attempt (albeit possibly subconscious) to mitigate the normalised extreme risk-taking that occurs in popular sports, thus making it comfortable for audiences to enjoy watching and following highly risky sporting endeavours. In contrast, coverage of injuries sustained off the field as 'freak accidents' may be understood in relation to the contracts signed by many professional athletes that preclude engaging in risky activities not associated with their professional sport. Such restrictions may create motivation to misrepresent the circumstances surrounding injuries resulting from prohibited activities as 'freak accidents'.

The typology that we developed offers a new way to study news coverage of injury events and insights into the potential risks and benefits of labelling an injury event a 'freak accident'. The creation of a two-dimensional typology of the framing of injury events as 'freak accidents' revealed that the expression takes on different meanings depending on context. Our qualitative analysis revealed considerable scope for incorporating a public health frame into these types of stories. Use of the expression 'freak accident' was seemingly called upon to deflect responsibility from one or more parties involved in the event. The possibility of 'accident' being associated with an alleviation of responsibility has not yet been a dominant theme in the ongoing debate of 'accident'.

\section{Limitations of the study}

These data are taken from only three news sources, one of which is explicitly national in scope (AP) and two that are associated with large eastern cities in the USA. The nature of the injury events covered elsewhere (eg, small town newspapers, newspapers from other regions or in other countries) may differ, which would impact the conclusions drawn. It is also possible that these findings are not generalisable to other media sources (such as television and internet news). Our sampling decisions were guided by both feasibility considerations and the fact that this is an exploratory study in an area where little or no previous research has been conducted.

Our decision to exclude exact replica stories but to include multiple distinct stories on a single injury event may affect our findings. Each of the stories in the sample does, however, represent a discreet opportunity to include a prevention message. Finally, our analysis is explicitly bound by the absence of any attempt to measure what impact journalists' framing has on readers' perceptions.

\section{What is already known on this subject}

- Many injury experts and institutions have rejected the use of the word 'accident' because it is thought to convey randomness and unpredictability, undermining notions of preventability.

- There is a disconnect between professional assumptions made about the connotations of 'accidents' and empirical studies of how audiences interpret this word in relation to injury events. 


\section{What is this study adds}

- The majority of news stories on injury events that were framed as 'freak accidents' pertained to injuries sustained by professional athletes.

- Fewer than 1 in 10 news stories on injury events framed as 'freak accidents' included a clear prevention message.

- News stories in which the journalist employed the expression 'freak accident' to describe an injury event were significantly less likely to include prevention information than those in which the expression came from a quote from a stakeholder involved in the event.

\section{CONCLUSIONS}

This analysis suggests a potentially missed opportunity for public health professionals to capitalise on the influence of the media by working to incorporate an injury prevention frame into stories of human injury. The subsequent impact of such efforts on public attitudes towards injury prevention would also warrant empirical evaluation.

Funding This paper was supported by the cooperative agreement number SR49CE001507 from the Centers for Disease Control and Prevention. Its contents are solely the responsibility of the authors and do not necessarily represent the official views of the Centres for Disease Control and Prevention.

Contributors This paper represents original work conducted by the seven authors listed. The research has been conducted over the previous year and is not currently in publication or under consideration elsewhere. The authorship team represents a collection of injury control advocates (DG, AG, SMB and SB) and communication scholars (KCS, JM and AS) and all authors contributed to the development of research questions and coding design as well as to data analysis and the final manuscript preparation.
Provenance and peer review Not commissioned; externally peer reviewed.

\section{REFERENCES}

1. Evans SA. Banning the "A word": where's the evidence? Inj Prev 2001;7:172-5

2. National Highway Traffic Safety Administration. 'Crashes aren't accidents' campaign. NHTSA Now 1997;3:1-2.

3. Davis RM, Pless B. BMJ bans 'accidents'. Accidents are not unpredictable. BMJ 2001;322:1320-1.

4. Girasek DC. How members of the public interpret the word accident. Inj Prev 1999;5:19-25

5. Blank D, Agranonik M, Marzola NR, et al. Academic Formation and Conceptions of Accident and Injury among Non-English Speaking Students: a Geometric Data Analysis Hard Look at Terminologisation and Injury Notions. Presentation at IP Safety. London, UK: World Conference, 2010

6. Hu X, Wesson D, Parkin P, et al. Pediatric injuries: parental knowledge, attitudes and needs. Can J Public Health 1996;87:101-5.

7. Holder HD, Treno AJ. Media advocacy in community prevention: news as a means to advance policy change. Addiction 1997;92(Suppl 2):s189-200.

8. Keays G, Pless IB. Impact of a celebrity death on children's injury-related emergency room visits. Can J Public Health 2010:101:115-18.

9. Sambrook PN, Chen JS, Simpson JM, et al. Impact of adverse news media on prescriptions for osteoporosis: effect on fractures and mortality. Med J Aust 2010;193:154-6.

10. Smith KC, Wakefield M, Terry-McElrath Y, et al. Relationship between newspaper coverage of tobacco issues on perceived smoking harm and smoking behavior among American teens. Tob Control 2008;17:17-24.

11. Wallack L, Dorfman L, Jernigan D, et al. Media Advocacy and Public Health. Powe for Prevention. Newbury Park, CA: Sage Publications, 1993.

12. Clarke JN, van Amerom GG. When bad things happen to good people. The portrayal of accidents in mass print magazines. Health Risk Soc 2007:9:425-39.

13. Dorfman L, Thorson DE, Stevens JE. Reporting on violence: bringing a public health perspective into the newsroom. Health Educ Behav 2001;28:402-19.

14. Smith KC, Cho J, Gielen A, et al. Newspaper coverage of residential fires: an opportunity for prevention communication. Inj Prev 2007:13:110-14.

15. Smith KC, Twum D, Gielen AC. Media coverage of celebrity DUls: teachable moments or problematic social modelling? Alcohol Alcohol 2009:44:256-60.

16. Bennett P, Calman K. Risk Communication and Public Health. New York: Oxford University Press, 1999

17. Guttman A. The appeal of violent sports. In: Guttman A, ed. Why We Watch: The Appeal of Violent Entertainment. Oxford: Oxford University Press, 1998.

\section{Paltry penalties for vehicular homicides}

A driver who failed to open her car door safely, killing a bicyclist, received a $\$ 100$ fine... and the sympathy of the victim's father. 'Well, I think the law is the law... I don't think she (the driver) meant to do it on purpose. It was carelessness.' In another so-called 'accident' that killed a 3-year-old in Montreal who was thrown from a car struck by another car, one of the drivers got a ticket for running a red light but neither was charged with a criminal offence.

\section{Australia considers making trampoline nets compulsory}

The Australian Standards Committee wants mandatory nets on all trampolines manufactured from 2012. Recent reports suggest that $27 \%$ of all trampoline injuries occurred because children fell off the trampoline. However, the coauthor of one report notes that '(nets) are a double-edged sword.... good if they're good enclosures but there is the possibility of strangulation.' http:// www.couriermail.com.au/business/netting-plan-has-jump-on-safety/story-fn7kjcme-12261983 